\title{
AS NOVAS CONFIGURAÇÕES FAMILIARES: O RELACIONAMENTO ENTRE OS EDUCADORES INFANTIS E AS FAMÍLIAS DAS CRIANÇAS
}

\author{
Suélen Cristiane Marcos \\ Universidade Estadual Paulista - UNESP, Faculdades de Ciência e Tecnologia, Pós - Graduação em Educação - CAPES, \\ Presidente Prudente, SP. e-mail: ssucris@hotmail.com
}

\begin{abstract}
RESUMO
Este artigo é fruto de uma pesquisa de mestrado que teve como objetivo avaliar as concepções de família presentes nos planos diretores, para saber se o valor que a elas é atribuído interfere na relação família e instituições de Educação Infantil, além de compreender as mudanças históricas da família e problematizar o papel da instituição de Educação Infantil no que diz respeito ao ensino de família. Optou-se pela pesquisa qualitativa, do tipo estudo de caso e pela técnica de análise documental dos planos diretores de instituições de Educação Infantil. Os resultados elucidaram que as concepções dos educadores sobre as famílias, se encontram fortemente baseadas no modelo nuclear dificultando a aceitação das novas configurações familiares e o estabelecimento de um relacionamento entre essas instituições. Quanto às formas de organização da família, contatamos que embora haja o predomínio da família nuclear, o número de famílias divergentes, do modelo nuclear, tem crescido.
\end{abstract}

Palavras - chave: Família, Educadores Infantis, Educação Infantil, Crianças, Concepções.

\section{THE FAMILY CONCEPTS PRESENT IN THE MASTER PLANSOF EARLY CHILDHOOD EDUCATION INSTITUTIONS}

\begin{abstract}
This article is the result of a research that aims to evaluate the concepts of family present in the master plans, to see if the value that is assigned to them interfere in family relationship and Child Education institutions, in addition to understanding the historical changes of family and discuss the role of the Early Childhood Education institution with regard to the teaching of family. We opted for the qualitative research, case study type and the technique of documentary analysis of master plans for Early Education institutions. The results elucidated that the conceptions of educators about families, are heavily based on nuclear model hindering the acceptance of new family configurations and the establishment of a relationship between these institutions. As for the forms of family organization, contacted that although the act predominance of the nuclear family, the number of different families, the nuclear model, has grown

Keywords: Family, Early Childhood Educators, Early Childhood Education, Children, Conceptions.
\end{abstract}




\section{INTRODUÇÃO}

Este artigo tem $o$ intuito de apresentar os resultados parciais da pesquisa intitulada "As concepções de família presentes nos planos diretores das instituições de Educação Infantil: avanços, contradições e possibilidades" que é vinculada ao curso de Mestrado do Programa de Pós-Graduação em Educação da Unesp de Presidente Prudente - SP e à Linha de Pesquisa "Educação e Infância".

Até pouco tempo atrás a família era definida simplesmente como sendo uma organização, entre os membros de um mesmo grupo sanguíneo, portanto determinada biologicamente, possuidora de um único núcleo sexual e afetivo, que envolve a relação existente entre um pai, uma mãe e filhos e no máximo a extensão deles, avós, tios e primos. Esta classificação nuclear de família tem entrado em conflito, com a saída nos últimos anos da clandestinidade, graças a intensas mudanças sociais e psíquicas, de famílias cuja organização vem se mostrando muito mais complexa e se contraposto a nuclear, como as monoparentais, adotivas, homossexuais, além disso, as inovações tecnológicas na área médica sobre reprodução humana, possibilitaram a formação de famílias antes nunca imaginadas na história da humanidade, organizadas com base em escolhas.
A experiência atual de família é complexa e pode envolver mais de um núcleo sexual-e, por conseqüência, familiar. É como se houvesse possibilidades permanentes de constituição e reconstrução desse grupo. (SOUZA, 2006, p.54).

Acreditando que as novas configurações familiares desafiem os educadores a entendê-las, aceitá-las e reconhecê-las como saudáveis ao desenvolvimento infantil, e mais ainda, a incluir essas diversas formas de ser família no momento em que ensinam as crianças sobre o que é a instituição familiar e o valor social a ela atribuído, buscamos saber quais as concepções que os educadores infantis têm sobre as famílias de seus alunos e se o valor que a elas atribuem interfere na relação família e instituição de Educação Infantil, e no alcance dos objetivos educacionais almejados pela instituição escolar, considerando que nas instituições de Educação Infantil a pareceria com as famílias é imprescindível para garantir a qualidade da formação oferecida pelo fato da prática educativa dessas instituições ser entendida, segundo a LDB/96, como "uma complementação a ação da família e da comunidade".

A educação infantil tem como finalidade 0 desenvolvimento integral 
da criança até seis anos de idade, em seus aspectos físico, psicológico, intelectual e social, complementando a ação da família e da comunidade. (Brasil, 1996, artigo 29).

Segundo as Diretrizes Curriculares Nacionais para a Educação Infantil (BRASIL. Ministério da Educação, 2009), as propostas pedagógicas das instituições de Educação Infantil devem possibilitar e garantir a participação, o diálogo, respeitar e valorizar as famílias de seus alunos, respeitando-as suas formas de estruturação.

Art 8.

1-na efetivação desse objetivo, as propostas pedagógicas das instituições de educação infantil deverão prever condições para o trabalho coletivo e para a organização de materiais, espaços e tempos que assegurem: III-a participação, o diálogo e a escuta cotidiana das famílias, o respeito e a valorização das suas formas de organização;

IV - o estabelecimento de uma relação efetiva com a comunidade local e de mecanismos que garantam a gestão democrática e a consideração dos saberes da comunidade;

Em decorrência da família nuclear ainda predominar no imaginário social como um modelo, dificulta muito a aceitação dos novos arranjos familiares, e os educadores também passam por essa dificuldade ao se depararem com famílias de educandos que fogem totalmente as suas idealizações e elaborações de família, sendo nesses casos muito comum um desvalor a elas atribuído e manifestações preconceituosas.

Existe uma grande
dificuldade em aceitar e
reconhecer os novos
arranjos familiares como
família. Infelizmente para
muitos, esses arranjos
constituem-se em desvios e
/ our famílias
"desestruturadas".
(CALDERÓN, GUIMARÃES,
1994, p.31)

Para que de fato exista um relacionamento entre as instituições de Educação Infantil e a família é preciso que os educadores passem a conceber a família como ela realmente é, uma organização sujeita as transformações para que seus membros se adaptem as necessidades que a vida vai trazendo, além disso, Oliveira nos adverte "que as condições de trabalho existentes em nossos dias dificultam a guarda da infância. Os membros familiares têm que lidar com diferentes ambientes que também estão em mudança". (OLIVEIRA, 2002, p.176) O fato de nem sempre a família, independente da sua estrutura, ser capaz de oferecer cuidado, afeto e proteção aos seus membros, como evidência os casos de violência doméstica, em todos os seus aspectos, não pode destruir a importância da 
família como uma instituição educativa dos seus filhos. As famílias não são iguais, se há falta do cumprimento de sua função em um número de famílias, isso não pode implicar generalizações, pois há muitas famílias de diferentes estruturas que se organizam e vivem tendo como eixo norteador o cuidado, proteção, sentimentos, desejos e interesses dos membros mais jovens, assim sendo, não podemos ser descrentes quanto à capacidade da família.

A visão negativa da família pode impedir e comprometer o estabelecimento de uma parceria entre as instituições de Educação Infantil e a família, já que implicaria o desrespeito dos educadores para com as famílias ao considerá-las incapazes de promover o desenvolvimento saudável de seus filhos e de contribuir para a prática pedagógica da escola.

A cultura da violência (física ou simbólica) presentes em muitas famílias (agressões, espancamentos, ameaças, castigos, humilhações), os abusos sexuais existentes em muitas delas, a diminuição da disponibilidade de tempo que os pais têm para ficar com os filhos, o conhecimento de casos de abandono da criança (desde não lhe trocar a fralda por muitas horas até trancá-la no quarto ou deixá-la por muito tempo vendo TV (arranham a imagem da família como ambiente protetor de sua prole, não obstante isso, a família não pode ser destituída de seu papel de importante agência educativa dos filhos em proveito da creche ou pré-escola). (OLIVEIRA, 2002, p.176-177).

Apesar da idealização da família, no contexto histórico que vivenciamos, as novas configurações familiares crescem em número e saem da clandestinidade, nos desafiam a aceitá-las e respeitá-las como formas de ser e de se viver a família. A aceitação das mesmas geralmente causa certo desconforto, pois implica num desequilíbrio da ordem social, por representar a quebra de tradições, de valores arraigados desde a modernidade.

O fato de os seres humanos enfrentarem mudanças e terem que se adequar a elas não é nenhuma novidade. $\mathrm{O}$ novo está na rapidez com que as mesmas ocorrem. Há muito pouco tempo atrás, esperava-se que o filho se comportasse e pensasse um pouco diferente de seu pai, que o neto apresentasse mudanças ainda mais significativas na forma de entender o mundo comparado a de seus avós. Hoje as mudanças, não esperam as novas gerações, ocorrem ao longo das nossas vidas, nos levando a buscar novos paradigmas.

A descontinuidade entre 0 modelo "tradicional" e a experiência vivida deflagra rupturas, pois as mudanças não ocorrem mais ao longo 
das gerações, como no passado histórico, mas sobre cada um de nós, muitas vezes em nosso ciclo individual. Essa rapidez implica conflito e desorientação, à medida que se torna necessário produzir novas respostas, ser moderno, atual. (SOUZA, 2006, p. 56).

De acordo com Stralton apesar das transformações sofridas pela família, essa instituição continua a ter grande importância para os seres humanos e para a vida social.

$\begin{aligned} & \text { Portanto, } \\ & \text { transformações } \\ & \text { nas socorridas } \\ & \text { sociedades }\end{aligned}$
industrializadas,
principalmente a partir de
meados do século XX,
provocaram alterações na
estrutura e na dinâmica das
relações familiares, o que
nos levar tentar
compreender a família
como um sistema
complexo, influenciado por
múltiplos fatores e eventos
internos e externos, que
sofre variações em função
dos contextos cultural,
social e histórico. No
entanto, a família ainda
continua sendo uma
instituição com forte
influência, mais um pouco
mais complexa do que as
imagens do passado nos
levariam a pensar
(STRALTON, 2003, p.337
apud DESSEN, 2007, p.18).

Neste contexto, nos preocupamos em saber se as mudanças na família afetaram o seu relacionamento com as instituições de Educação Infantil e se as famílias reais das crianças são aceitas e reconhecidas como parceiras pelos educadores infantis. Para responder a essas indagações este trabalho foi escrito.

\section{METODOLOGIA}

A pesquisa, foi aprovada pelo comitê de ética e pesquisa da FCT-UNESP, como consta o protocolo 73/2011 e fundamenta-se na abordagem qualitativa do tipo estudo de caso, pois tem como foco as instituições de Educação Infantil de uma cidade do interior do estado de São Paulo. Nas palavras de Ludke e André (1986, p.18-19) os estudos de caso:

Enfatizam a "interpretação
em contexto". Um princípio
básico desse tipo de estudo
é que, para uma apreensão
mais completa do objeto, é
preciso levar em conta o
contexto em que ele se
situa. Assim para
compreender melhor a
manifestação geral de um
problema, as ações, as
percepções, os
comportamentos e as
interações das pessoas
devem ser relacionados à
situação específica onde
ocorrem ou à problemática
determinada a que estão
ligadas.

Para obter os dados da pesquisa, fezse uso da técnica de análise documental, que 
segundo Caulley (apud LUDKE; ANDRÉ, 1986, p.38) "busca identificar informações factuais nos documentos a partir de questões ou hipóteses de interesse".

No caso desta pesquisa, o estudo se focou nos planos diretores das instituições de Educação Infantil, com o objetivo de ter acesso aos dados sobre as famílias das crianças e a partir deles compreendê-las com base na realidade. Também nos preocupamos em identificar, analisar e avaliar as concepções dos educadores sobre a família dos seus educandos e qual a influência delas no relacionamento entre as instituições de Educação Infantil e a família. Por meio dos planos de ensino, contidos no plano diretor, averiguamos como os docentes planejam ensinar na atualidade o que é ser família para as crianças, sendo a integração de todos esses elementos que nos levam a configurar a complexidade do relacionamento família e I.E.I.

O município estudado conta, segundo dados de 2010, da Secretaria Municipal de Educação, com 42 instituições de Educação Infantil. Devido o tempo disponibilizado a uma pesquisa de mestrado, não foi possível averiguarmos o plano diretor de todas essas escolas, então as delimitamos pela sua localização geográfica. Assim sendo, foi sorteada uma escola de cada região da cidade (norte, sul, leste, oeste, central), que atendia crianças de 4 a 5 anos. Tal escolha se justifica na tentativa de englobar as diferenças regionais, sociais, econômicas e de clientela existentes na realidade pesquisada.

Os dados aqui apresentados foram retirados dos planos diretores de cinco instituições de Educação Infantil. Em respeito às normas éticas de condutas de uma pesquisa nomeamos as instituições de Educação Infantil de acordo com a região em que se localizam, I.E. I; Leste; I.E. I Oeste, I.E. I Central; I.E. I Norte e I.E.I. Sul.

O plano diretor é um documento oficial da escola, sendo sua construção coletiva uma exigência dos órgãos educacionais. Tal documento dá validade e legalidade ao funcionamento e aos objetivos pedagógicos das instituições de ensino e tem como finalidade central elucidar a proposta pedagógica de cada unidade escolar, levando em conta a realidade da instituição e dos alunos.

\section{AS ESTRUTURAS FAMILIARES DAS CRIANÇAS}

Com o objetivo de identificarmos a família das crianças, do ponto de vista da sua estrutura analisamos os planos diretores das instituições de Educação Infantil na expectativa de identificar quais são as formas de organização das famílias das crianças.

Os autores dos planos diretores obtiveram essas informações, junto às famílias de suas crianças, por meio de uma entrevista realizada no início do ano de 2010. 
Segundo os autores do documento, a maioria dos responsáveis pelas crianças respondeu a solicitação da escola.

As informações sobre a constituição familiar oferecidas pelos pais à instituição de Educação Infantil revelam que há o predomínio da estrutura nuclear (I.E.I. Sul $82 \%$, I.E.I. Leste $72 \%$, I.E.I. Central $82,1 \%$, I.E.I. Norte $75,5 \%)$. O que é corroborado com a afirmação dos autores do plano diretor da I.E.I. Norte que sobre as estruturas familiares das crianças, explicitam que "a maioria mora com os pais e estes são casados" (PRESIDENTE, PRUDENTE. Secretaria Municipal de Educação, 2010-2012, p.1).

A separação comparece como uma categoria definida pelas instituições de Educação Infantil ao caracterizar a família, tendo como critério a separação considerada por duas situações: a separação entre os casais e a separação pela morte (viúvos). A separação dos pais tem se tornado cada vez mais comum em nossa sociedade e não mais se traduz por casos isolados. O Educador e sociólogo Cabrera (2012), ao comentar o aumento do número de divórcios, segundo o censo demográfico de 2010 do IBGE, analisa:

A atual geração é flexível não quer nada sólido, e sim mudanças rápidas. $\mathrm{A}$ sociedade está imediatista, o que gera novos comportamentos [....] Divórcio, hoje, não é mais problema. Se um casal se separa, ele pode casar novamente. Isso tem acontecido, mas não dentro da igreja, pelo fato do catolicismo não permitir, acarretando, desse modo, na diminuição de cerimônias religiosas (CABRERA, 2012, p.7b).

Nota-se também o número expressivo de famílias que tem como chefes as mulheres (I.E.I. Sul 16\%, I.E.I. Leste 22\%, I.E.I. Central 15,3\%, I.E.I. Norte 17,56\%).

Atualmente, as mulheres têm assumido a responsabilidade pelo cuidado dos filhos. Esta configuração familiar é uma das que mais comparece nas informações sobre as famílias das crianças das instituições de Educação infantil em questão, perdendo apenas para tradicional nuclear (pai, mãe e filhos). É ínfima a porcentagem dos pais que cuidam sozinhos dos filhos, na maioria das I. E. I. representa $1 \%$. A instituição de Educação Infantil Leste é a única em que se constatou que $3 \%$ das crianças moram apenas com o pai.

É possível constatar, também, que algumas crianças têm como responsáveis os avós. Na Instituição de Educação Infantil Leste, sobre a estrutura familiar das crianças, os autores do plano diretor afirmam que:

Nossa clientela provém em sua maioria de famílias de classe baixa, muitas nas quais é a mãe que sustenta a casa. Há também casos em que a criança mora somente com o pai, outras 
vezes são os avós que mantém a guarda dessas crianças, pois os pais estão presos, por tráfico de drogas, ou simplesmente foram embora, abandonando seus filhos. (PRESIDENTE PRUDENTE. Secretaria Municipal de Educação, 2010-2012, p.1011).

Também chama atenção o número de pais que optaram por não se casar e permanecerem solteiros, um porcentual, na maioria das instituições de Educação Infantil de no mínimo 9\%, que não pode ser ignorado, apenas a I.E.I. Central tem um porcentual menor, $2 \%$ dos pais não são casados.

O plano diretor da Instituição de Educação Infantil Oeste não possui a tabulação das entrevistas com os familiares. Admitem apenas que: "o responsável pelas crianças são na maioria os pais e/ou somente as mães. Temos alguns casos de avós, tios e um caso de somente o pai cuidam" (PRESIDENTE PRUDENTE. Secretaria Municipal de Educação, 2010-2012, p.9).

Pelo exposto, as estruturas familiares das crianças expressas nos planos diretores comprovam que o modelo nuclear de família, embora predominante, não representa a única forma de se constituir família na contemporaneidade. Novas formas de estruturação mais complexa têm se contraposto a nuclear (pai, mãe e filhos).
As informações dos responsáveis pelas crianças sobre a instituição familiar estão em consonância com as contidas no Censo 2010, que apontam que as famílias brasileiras apresentam uma estrutura bem mais diversa do que a clássica, pai, mãe e filhos.

Até 1990 famílias cuja estrutura se apresentasse diferente da nuclear eram raras.

Os dados divulgados, em 2011, pelo Instituto Brasileiro de Geografia e Estatística (IBGE), revelaram que a vida privada dos brasileiros se alterou profundamente, sendo as transformações relacionadas à instituição familiar, que mais saltam a nossa percepção. A instituição familiar está mais fragmentada, $15 \%$ das mesmas se constituem de mulheres que vivem sozinhas com seus filhos sem a presença dos pais das crianças, dessa referida população algumas mulheres são viúvas, todavia, a maioria delas é separada ou é mãe solteira.

Os planos diretores analisados evidenciaram também um número expressivo de mães que cuidam sozinhas de sua prole.

Segundo censo 2010 cresce cada vez mais o número de mulheres que se declaram "chefes de famílias", passando de $27 \%$ em 2000, para 38\% em 2010. Com esses dados, é possível entender as mulheres "chefes de famílias" como as principais responsáveis 
pelas decisões que envolvem a família, que podem ou não ter um companheiro. Em 8\% das moradias brasileiras, há crianças que são filhos de apenas um dos conjugues e as uniões consensuais informais subiram de $29 \%$ para $36 \%$.

Parece evidente, tanto pelas informações prestadas pelos responsáveis das crianças como nos dados veiculados pelo IBGE, sobre a família brasileira, que a família mudou. Isso só foi possível graças a intensas mudanças sociais, econômicas e psicológicas, que ofereceram uma abertura cultural para que as inovações familiares ocorressem.

\section{CONCLUSÃO}

Os resultados obtidos a respeito das estruturas familiares das crianças evidenciaram que as famílias são predominantemente nucleares, todavia, as famílias, cuja organização difere do modelo nuclear, representam uma porcentagem expressiva. A realidade das famílias das crianças comprova que não existe um modelo único de família e sim uma instituição sujeita a muitas variações de acordo com o contexto histórico, social e cultural.

A não aceitação, por parte dos educadores infantis, dos novos arranjos familiares como possibilidades de famílias saudáveis e adequadas ao desenvolvimento infantil é um fator impeditivo para o relacionamento entre as instituições de Educação Infantil e a família. Defendemos ser necessário que os educadores infantis entendam a instituição familiar, não mais, com base em um modelo, mas que sejam capazes de valorizar a forma de ser, organizar, relacionar de cada família, pois o mais importante nesta instituição não é a sua estrutura, mas o oferecimento de afeto e proteção para os seus membros.

Esperamos que reflexões sobre o problema desta pesquisa e melhoria na formação desses educadores, novos estudos e pesquisas, possibilitem que os educadores infantis reconheçam como importante para a qualidade da Educação Infantil, assim como, um direito da criança e de sua família, a parceria com as famílias e que esse reconhecimento torne o discurso em defesa da parceira com as famílias um realidade, acabando com as contradições entre o que se diz e o que se faz.

\section{REFERÊNCIAS}

BRASIL. Lei de Diretrizes e Bases da Educação Nacional. Lei no. 9.394/96, de 20 de dezembro de 1996. Brasília: Ministério da Educação, 1996.

BRASIL. Ministério da Educação. Resolução CEB n.o de 17 de Dezembro de 2009. Fixa as Diretrizes Curriculares Nacionais para a Educação Infantil. Brasília: Ministério da Educação, 2009.

CABRERA, L.A.S. Número de uniões informais lidera na região. Jornal $\mathbf{O}$ Imparcial, 
Presidente Prudente, 18 out. 2012, Cidades, p.7b.

CALDERÓN, A. I; GUIMARÃES, R. F. Família: a crise do modelo hegemônico. São Paulo: Cortez, 1994.

DESSEN, M. A. A família como contexto de desenvolvimento. In: FLEITH, D.S. A construção de práticas educacionais para alunos com altas habilidades/ superdotação. Brasília: Ministério da Educação, 2007. V.3, p.9-28.

LUDKE, M.; ANDRÉ, M.E.D.A. Pesquisa em educação: abordagens qualitativas. São Paulo: E.P.U, 1986.

OLIVEIRA, Z. M. R. Educação infantil: fundamentos e métodos. São Paulo: Cortez, 2002. p.256.

PRESIDENTE PRUDENTE. Secretaria Municipal de Educação. Planos Diretores, instituições de Educação infantil Sul, Leste, Norte, Oeste e Central. Presidente Prudente: Secretaria Municipal de Educação, 2010-2012.

SOUZA, M. R. Configurações plurais. In: Revista mente e cérebro. São Paulo: Duetto, 2006. p.52-65.

Recebido para publicação em 11/08/2014

Revisado em 25/08/2014

Aceito em 29/08/2014 